\title{
Autoantibody-associated psychiatric syndromes in children: link to adult psychiatry
}

\author{
Niels Hansen ${ }^{1} \cdot$ Daniel Luedecke ${ }^{3} \cdot$ Berend Malchow $^{1} \cdot$ Michael Lipp $^{3}$. Jonathan Vogelgsang ${ }^{1} \cdot$ Charles Timäus $^{1}$. \\ Tristan Zindler $^{2}$ - Stefan Gingele ${ }^{4}$. Simone Kühn ${ }^{3}$. Jürgen Gallinat ${ }^{3} \cdot$ Klaus Wiedemann $^{3}$. Johannes Denk ${ }^{3}$. \\ Nicole Moschny ${ }^{2}$. Jens Fiehler ${ }^{7}$. Thomas Skripuletz ${ }^{4} \cdot$ Christian Riedel $^{6} \cdot$ Mike P. Wattjes $^{8} \cdot$ Inga Zerr $^{5}$. \\ Hermann Esselmann ${ }^{1} \cdot$ Luise Poustka $^{9} \cdot$ Anne Karow $^{3} \cdot$ Hans Hartmann $^{10} \cdot$ Helge Frieling $^{2} \cdot$ Stefan Bleich $^{2}$. \\ Jens Wiltfang ${ }^{1,11,12}$ - Alexandra Neyazi ${ }^{2}$ + CAP (Cerebrospinal Fluid Analysis in Psychiatry)-Consortium
}

Received: 16 January 2021 / Accepted: 13 May 2021 / Published online: 31 May 2021

(C) The Author(s) 2021

\begin{abstract}
Studies show that psychiatric symptoms in adults and children are sometimes associated with serum neural autoantibodies. The significance of serum neural autoantibodies associated with psychiatric symptoms in children remains often unclear, but might be relevant for the extent and occurrence of psychiatric disease manifestation in later life, as well as therapy and outcome. For this narrative review, we sought articles listed in PubMed and published between 1988 and 2020 addressing the maternal-fetal transfer of neural autoantibodies and psychiatric disorders associated with serum neural autoantibodies. We identified six major subgroups of psychiatric disorders in children that are associated with serum neural autoantibodies: patients with attentional deficit hyperactivity disorder, autism spectrum disorder, obsessive compulsive disorder, Gilles de la Tourette syndrome, psychosis and catatonia. Furthermore, we summarized study findings from maternal-fetal transfer of Contactin-associated protein-like 2, $\mathrm{N}$-methyl-D-aspartate receptor and fetal brain autoantibodies associated with behavioral effects in animals and humans. We hypothesize that the maternal transfer of serum neuronal autoantibodies during or after birth could result (1) in the ignition of an autoimmune-mediated inflammation having neurodevelopmental consequences for their children (autoimmune-priming-attack hypothesis) and (2) has a potential impact on the later manifestation of psychiatric disorders. Through this narrative review, we propose a diagnostic pathway for the clinical diagnosis of a potentially autoimmune origin of psychiatric symptoms in children while considering recent guidelines.
\end{abstract}

Niels Hansen

niels.hansen@med.uni-goettingen.de

1 Department of Psychiatry and Psychotherapy, University Medical Center Goettingen, Von-Siebold-Str. 5, 37075 Göttingen, Germany

2 Department of Psychiatry, Social Psychiatry and Psychotherapy, Hannover Medical School, Carl-Neuberg Str. 1, 30625 Hannover, Germany

3 Department of Psychiatry and Psychotherapy, University Hospital Hamburg-Eppendorf, Martinistr. 52, 20251 Hamburg, Germany

4 Department of Neurology, Hannover Medical School, Carl-Neuberg Str. 1, 30625 Hannover, Germany

5 Department of Neurology, University Medical Center Göttingen, Robert-Koch Str. 40, 37075 Göttingen, Germany

6 Department of Neuroradiology, University Medical Center Göttingen, Robert-Koch Str. 40, 37075 Göttingen, Germany
7 Department of Neuroradiology, University Hospital Hamburg-Eppendorf, Martinistr. 52, 20251 Hamburg, Germany

8 Department of Neuroradiology, Hannover Medical School, Carl-Neuberg Str. 1, 30625 Hannover, Germany

9 Department of Childhood and Adolescence Psychiatry, University Medical Center Göttingen, Robert-Koch Str. 40, 37075 Göttingen, Germany

10 Clinic for Pediatric Kidney, Liver and Metabolic Diseases, Hannover Medical School, Carl-Neuberg Str. 1, 30625 Hannover, Germany

11 German Center for Neurodegenerative Diseases (DZNE), Von-Siebold-Str. 3a, 37075 Göttingen, Germany

12 Neurosciences and Signaling Group, Department of Medical Sciences, Institute of Biomedicine (iBiMED), University of Aveiro, Aveiro, Portugal 


\section{Introduction}

Autoimmune-mediated encephalitis in children manifests with an acute or subacute neuropsychiatric syndrome concomitant with paraclinical findings and/or underlying neuronal autoantibodies lasting less than three months (Cellucci et al. 2020). Pediatric autoimmune encephalitis is characterized in particular by features such as prodromal fever, multifocal seizures, and a relapse-remitting course in addition to the typical features of autoimmune encephalitis also observed in adults ranging from seizures to psychiatric abnormalities and memory disturbances (Cellucci et al. 2020). The psychiatric symptom-spectrum often comprises the symptoms such as a stereotypical behavior, hyperactivity, hypersexuality, insomnia, mood dysfunction, psychosis or mild behavioral changes (Cellucci et al. 2020; Hacohen et al. 2013; Titulaer et al. 2013; Armangue et al. 2015; Florance et al. 2009). Neural autoantibodies detected in patients with pediatric autoimmune encephalitis can be divided into antibodies against membrane surface antigens such as anti- $N$-methyl-D-aspartate receptor (NMDAR), anti-myelin oligodendrocytic glycoprotein (MOG) antibodies, and antibodies against intracellular antigens such as anti-glutamic acid decarboxylase 65 (GAD65) antibodies. Much more seldom are the following cell-surface antibodies identified in children with autoimmune encephalitis: antibodies against the anti-dopamine 2 (DR2) receptor, gamma aminobutyric acid A/B receptor (GABAA/B)-receptor, glycin-receptor and metabotropic glutamate receptor 5 (mGluR5) (Cellucci et al. 2020). The latest evidence suggests that only those antibodies that target cell-surface antigens are pathogenic, but not those against intracellular antigens. Pediatric autoimmune encephalitis should be distinguished from the clinical diagnosis of PANS (pediatric acute-onset neuropsychiatric syndrome) (for differential diagnosis, Fig. 1), which is characterized by an abrupt onset of obsessive compulsive disorder (OCD) or heavily restricted food intake and more than two additional symptoms in terms of anxiety, aggression, behavioral, sensory or motor abnormalities or sleep dysfunction (for review, see Murphy et al. 2014). The PANS criteria were introduced to describe syndromes with a suspected trigger (e.g., infectious or environmental), and modified by the PANDAS (Pediatric Autoimmune Neuropsychiatric Disorders Associated with Streptococcal Infections) criteria, which entail a tic disorder also, and prior streptococcal infections with antibodies against streptococcal proteins, human brain enolase or neural tissue (Nicollini et al. 2015; Shimasaki et al. 2020) or calcium/calmodulin-dependent protein $(\mathrm{CaM})$ kinase II activity (Kirvan et al. 2003, 2006; Chain et al. 2020). Co-occurring antinuclear antibodies (ANA) and elevated
FIRES

HASHIMOTO ENCEPHALOPATHY LUPUS ERYTHEMATOSUS PANS PANDAS RASMUSSEN ENCEPHALITIS

Fig. 1 Important differential diagnoses limited to autoimmune pediatric disorders. The following differential diagnoses of pediatric autoimmune disorders have to be considered in prior to assume a pediatric autoantibody-associated psychiatric syndrome. FIRES febrile infection-related epilepsy syndrome, PANS pediatric acute-onset neuropsychiatric syndrome, PANDAS pediatric autoimmune neuropsychiatric disorders associated with streptococcal infections

anti-thyroid antibodies have been detected in some patients with diagnosed PANS (Gromark et al. 2019). However, it is currently debatable whether PANS and PANDAS are independent disease entities that can be separated from tics or OCD (Gilbert et al. 2019). Furthermore, other rare childhood diseases should be considered as differential diagnoses, such as Rasmussen encephalitis, a neuroinflammation limited to one brain hemisphere causing severe cognitive dysfunction and drug-resistant epilepsy (Varadkar et al. 2014) (Fig. 1). In addition, FIRES (febrile infection-related epilepsy syndrome) is another childhood epilepsy syndrome involving febrile infection preceding seizures (Hon et al. 2018). Hashimoto encephalopathy is another autoimmune condition in children that is essential to consider, as it encompasses an encephalopathy-causing cognitive dysfunction and neuropsychiatric symptoms due to thyroid autoantibodies (anti-thyreoglobulin and antithyroid peroxidase) (Mattozzi et al. 2020). Furthermore, it is advisable to screen for autoantibodies associated with systemic lupus erythematosus entailing neuropsychiatric features, such as anti-ds DNA (double-stranded desoxyribonucleic acid antibodies) and anti-antiphospholipid antibodies in children, as psychiatric syndromes such as depression and anxiety often accompany childhood-onset lupus erythematosus (Quilter et al. 2019).

Besides these pediatric syndromes, psychiatric symptomatology may be due to an autoimmune process without obvious organic symptoms or paraclinical findings derived from the criteria for autoimmune encephalitis according to Cellucci et al. (2020). In this article, we briefly describe the criteria and a developed diagnostic pathway for autoimmune-based psychiatric symptoms in children (Fig. 2). 


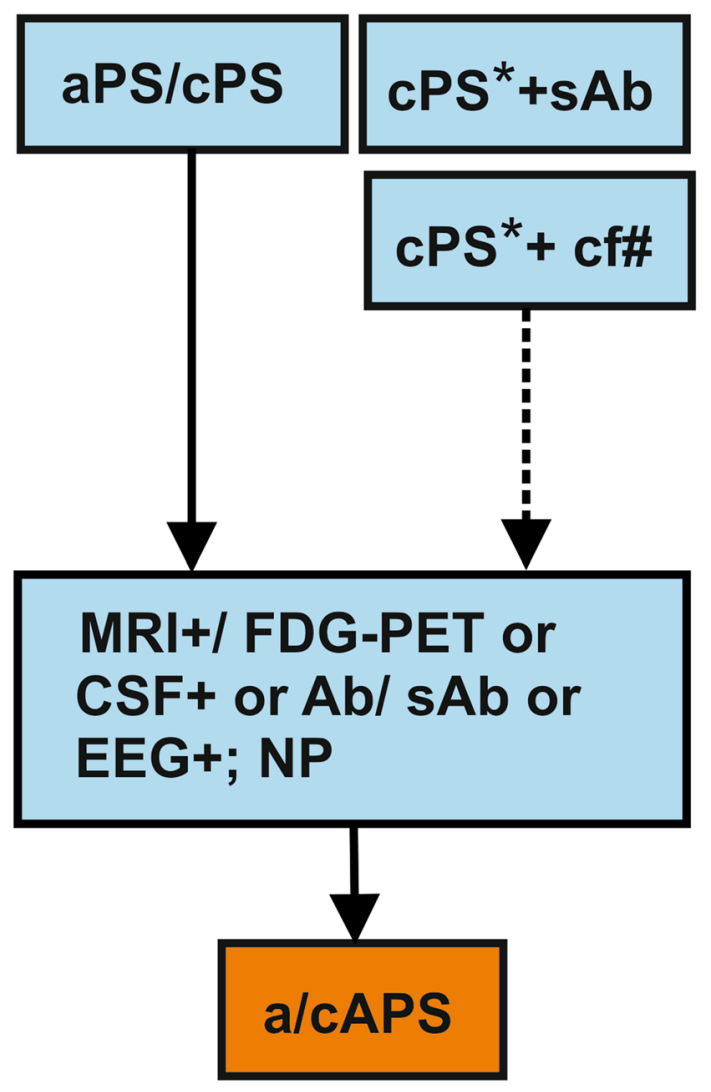

Fig. 2 Diagnostic pathway for the diagnostics of pediatric neural autoantibody-associated psychiatric symptoms. Figure illustrates a simplified diagnostic pathway. Consider in particular subacute (aPS) or subchronic (cPS) psychiatric syndrome with the following suspected diagnosis subgroups $[*=$ schizophrenia spectrum disorders, obsessive-compulsive disorder, autism spectrum disorders, attention deficit hyperactivity disorder, Gilles de la Tourette's syndrome/tic disorder, catatonia] and one symptom from the following symptom cluster $[\#=$ psychosis, obsessive-compulsive, autistic or impulsive behavior, catatonia and sleep dysfunction]. Differential diagnoses encompassing other disease entities involving the immune system must be thoroughly considered (Fig. 1). If prior diagnostics have already been done in cPS (cPS*), serum neural autoantibodies (sAb) or $\geq 2$ clinical features (Table 2) justify additional diagnostics (EEG, MRI/FDG-PET or CSF). A $b$ neural autoantibodies, $a / c$ APS subacute or subchronic autoimmune psychiatric syndrome, a/c PS subacute or subchronic psychiatric syndrome, CSF cerebrospinal fluid, $E E G$ electroencephalography, $N P$ neuropsychological testing, $F D G$ $P E T$ fluorodesoxyglucose positron emissions tomography, MRI magnetic resonance imaging, $s A b$ serum neural autoantibodies. *Means cPS with prior diagnostics (EEG, MRI, CSF). $c P S^{*}+s A b / c f$ cPS with prior diagnostics and presence of serum neural autoantibodies or clinical features. MRI+ MRI suggestive of encephalitis, CSF + pleocytosis in CSF, $E E G+$ focal or generalized epileptic potentials or slowing, $c f \#=\geq 2$ clinical features

\section{Methods}

We looked for articles listed in PubMed and published between 1988 and 2020 (23 September 2020) for the terms "psychiatry antibody children/pediatric/paediatric" or "psychiatry autoantibody children/pediatric/paediatric". After this first screen, we searched Pubmed for the items "OCD children/pediatric/paediatric antibody" or "ADHD (attention deficit hyperactivity disorder) children/pediatric/ paediatric antibody" or "autism children/pediatric/paediatric antibody" "Gilles de la Tourette syndrome (TS) children/ pediatric/paediatric antibody " or "psychosis children/pediatric/paediatric antibody" or "maternal transfer autoantibody children/pediatric/paediatric" or "catatonia psychiatry antibody children/pediatric/paediatric". We reported relevant studies showing an association between serum or cerebrospinal fluid (CSF) autoantibodies and reported psychiatric disorders [psychosis, catatonia, TS, ADHD, OCD, autism spectrum disorder (ASD)] in our narrative review below.

\section{Results}

\section{Maternal-fetal transfer of autoantibodies}

We present animal and human research data from the literature concerning the maternal-fetal transfer of autoantibodies, which can severely affect the neurodevelopment of the fetus or newborn child, with consequences for later behavioral abnormalities potentially culminating in disorders such as ADHD or ASD. In general, maternal immunoglobulin G begins to cross the placenta at the beginning of the second trimester (Palmeira et al. 2012). The blood-brain barrier is not fully developed then. The fetal brain is thus theoretically susceptible to antibodies-even though the mother might be unaffected due to her functioning blood-brain barrier. So far, three groups of autoantibodies against membrane surface antigens have been identified in conjunction with maternal-fetal transfer: (1) $\mathrm{N}$-methyl-D-aspartate receptor (NMDAR) antibodies (Wang et al. 2012; Jurek et al. 2019; Lee et al. 2009a), (2) Contactin-associated protein-like 2 (CASPR2) antibodies (Coutinho et al. 2017a, b; Brimberg et al. 2016; Bagnall-Moreau et al. 2020) and (3) antibodies against the 37 and $73 \mathrm{kDa}$ proteins (Braunschweig et al. 2013). Furthermore, although our review focuses on membrane surface autoantibodies, we call brief attention to evidence of the maternal-fetal transfer of anti-Sjögren'ssyndrome-related antigen A (SSA) (Ro) and anti-SSB (La) and anti-ribonucleoprotein 1 (RNP) autoantibodies in mothers with lupus erythematosus (Feki et al. 2015, Zurgil et al. 1993) to better decipher the spectrum of potential maternal-fetal transfer of autoantibodies.

\section{Maternal-fetal transfer of $\mathrm{N}$-methyl-D-aspartate receptors autoantibodies}

Several studies Wang et al. (2012), Jurek et al. (2019), Lee et al. (2009a; b) addressed the effects of different NMDAR 
antibodies' exposure of mice in utero. Wang et al. (2012) observed that specific NR2A-expressing neuronal apoptosis can be induced within the murine female brainstem after the application of double-stranded desoxyribonucleotide acid (DNA) antibodies that cross-react with the NMDAR's NR2A and NR2B subunits. They demonstrated how these antibodies may enter brain parenchyma and result in neuronal brain damage. In addition to studying such neuropathological changes caused by infiltrating autoantibodies, Jurek et al. (2019) investigated the long-term behavioral consequences by assessing the behavioral reaction of mice after being given NMDAR antibodies during pregnancy. The transfer of human recombinant immunoglobulin 1 (IgG1) NR1 (GluN1) subunit of NMDAR antibodies resulted in long-term dysfunctional rodent behavior revealing rising mortality, sensory and motor impairment, and hyperlocomotion. In particular, hyperlocomotion in different rodent models could represent a cardinal feature of psychiatric disorders such as ADHD (Zimmermann et al. 2015) or mania (Souza et al. 2014). The rodent model is a surrogate model for the effects of NMDAR antibodies in humans suggesting structural and functional consequences following the maternal-fetal transfer of NMDAR autoantibodies and leading to behavioral abnormalities. Concerning humans, recent data [2010-2019 from Dalmau (2020)] indicate that neonatal mortality is low and children of mothers with NMDAR encephalitis do not suffer from further symptoms over time. Thus, the relevance of NMDAR antibodies in children is unclear and requires further investigation. Animal studies suggest an association between dysfunctional neurodevelopment and NMDAR antibodies, although the mechanism is still unclear. However, these results might implicate that a mother's NMDAR encephalitis during pregnancy could lead to severe behavioral disability in her offspring, and enable an "autoimmune hit" during neuronal development.

\section{Maternal-fetal transfer of contactin-associated protein-like 2 autoantibodies}

Our literature research revealed studies Coutinho et al. (2017a, b), Brimberg et al. (2016), Bagnall-Moreau et al. (2020) demonstrating effects on brain structure and function by the maternal-fetal transfer of CASPR2 autoantibodies. Coutinho et al. (2017a, b) inspected the amount and distribution of glutamatergic synapses within the somatosensory and prefrontal cortex. They observed an alteration in the distribution of glutamatergic synapses within the somatosensory cortex. Furthermore, the numbers of glutamatergic synapses were decreased in the prefrontal and somatosensory cortex. Such aberrations in the composition and distribution of glutamatergic synapses are compatible with a hypothetical etiology of psychiatric disorders such as autism and schizophrenia (Coley and Gao 2018). To ignite brain inflammation, the activation of phagocytes in the central nervous system (termed microglia) seems to play a decisive role (Sousa et al. 2018). Coutinho noted more activated microglia in mice receiving CASPR2 antibodies compared to controls. Their findings indicate an immune activation responsible for persistent brain inflammation in mice. The upregulation of activated microglia and reduction (e.g. elimination) in glutamatergic synapses is a phenomenon called synaptic pruning. Inflated synaptic pruning has been associated with neurodevelopmental disorders such autism and schizophrenia (Neniskyte and Gross 2017). There is also evidence that knockdown of the CASPR2 (CNTNAP2) gene might affect dendritic spine density (as a crucial part of the neuron relevant for sufficient neurotransmission). Levels of glutamatergic receptors such as GluA1 subunits of AMPA receptors in murine dendritic spines might be altered (Varea et al. 2015), so that balanced excitatory glutamatergic neurotransmission might be disturbed. Furthermore, the altered dendritic morphology of excitatory neurons in the hippocampus is further corroborated by the maternal-fetal transfer from man to mice study, according to data from Brimberg et al. (2016). Their findings could imply substantial alterations within neuronal transmission. Alterations in neuronal excitatory transmission could lead to the generation of psychiatric symptoms such as psychosis via glutamatergic hypofunction as the "glutamate hypothesis" proposes (Kim et al. 1980). Furthermore, aberrant dendritic morphology is evident in neurodevelopmental disorders such as autism (Ma et al. 2019). In turn, CASPR2 autoantibodies could lead to structurally altered dendrites, thereby linking neurodevelopment disorders to initial autoimmunity with CASPR2 autoantibodies. In addition to structural abnormalities, deficiencies in cortical development, social capacities, learning, and repetitive behavior are observed in mice exposed in utero to monoclonal CASPR2 antibodies (Bagnall-Moreau et al. 2020). Furthermore, male mice in particular born to dams harboring polyclonal anti-CASPR2 antibodies exhibit the aforementioned abnormalities in cortical development and dendritic complexity of excitatory neurons, as well as behavioral deficits (Bagnall-Moreau et al. 2020). ASD demonstrates pronounced male predominance also; intriguingly, the CNTNAP2 mutation-related ASD phenotypes are also more frequent in males, suggesting a sex-associated susceptibility to anomalies in CASPR2 functioning (Alarcón et al. 2008; Bien et al. 2017). However, the role of CASPR2 autoantibodies in autism is controversial, as one study showed elevated CASPR2 autoantibodies in pregnant women who had children who were mental retarded, but not autistic (Coutinho et al. 2017a, b). In conclusion, the transfer of CASPR2 autoantibodies in rodents could result in major structural and functional deficits in neurodevelopment, suggesting the pathogenic potential of CASPR2 autoantibodies for human neuronal development. 
Table 1 Psychiatric disorders and psychiatric syndromes associated with autoantibodies in children

\begin{tabular}{|c|c|c|c|c|c|}
\hline Disorders/symptoms & $n$ & ABS associated & Material & Test & References \\
\hline \multicolumn{6}{|c|}{$\begin{array}{l}\text { Psychiatric disorders/syn- } \\
\text { dromes }\end{array}$} \\
\hline Psychosis & $9 / 43$ & DR2, NMDAR, LGI1 & Serum & fCyt, live CBA & Pathmanandavel et al. (2015) \\
\hline \multirow[t]{2}{*}{ ADHD } & $4 / 15$ & GAD65 & Serum & $\begin{array}{l}\text { ELISA, immunohistochemis- } \\
\text { try mice brain tissue }\end{array}$ & Rout et al. (2012) \\
\hline & 15 & DAT & Serum & ELISA & Giana et al. (2015) \\
\hline \multirow[t]{4}{*}{ ASD } & $2 / 37,5 / 37,11 / 37$ & $37,39,73 \mathrm{kDa}$ & Serum & $\begin{array}{l}\text { Western blot, rhesus } \\
\text { macaque brain tissue }\end{array}$ & Rossi et al. (2013) \\
\hline & $95 / 355$ & $45,62 \mathrm{kDa}$ & Serum & $\begin{array}{l}\text { Western blot, rhesus } \\
\text { macaque brain tissue }\end{array}$ & Piras et al. (2014) \\
\hline & 20 & Frontal cortex & Serum & $\begin{array}{l}\text { Radial immunodiffusion } \\
\text { assay }\end{array}$ & Todd et al. (1988) \\
\hline & $3 / 20$ & GAD65 & Serum & $\begin{array}{l}\text { ELISA, immunohistochemis- } \\
\text { try mice brain tissue }\end{array}$ & Rout et al. (2012) \\
\hline \multirow[t]{3}{*}{ OCD } & $7 / 21$ & $55,86 \mathrm{kDa}$ & Serum & $\begin{array}{l}\text { Immunoblot, immunohisto- } \\
\text { chemistry }\end{array}$ & Morer et al. (2008) \\
\hline & $21 / 50$ & ABGA & Serum & Western blot, ELISA & Dale et al. (2005) \\
\hline & $261 / 311$ & DR1, LG & Serum & $\begin{array}{l}\text { ELISA, human neuronal cell } \\
\text { line }\end{array}$ & Cox et al. (2015) \\
\hline Mental retardation & $1 / 11$ & CASPR2 & Serum & Live CBA & Coutinho et al. (2017a, b) \\
\hline
\end{tabular}

$A B G A$ anti basal ganglia antibodies, $A D H D$ attention deficit hyperactive disorder, AMPAR $\alpha$-amino-3-hydroxy-5-methyl-4-isoxazolepropionic acid, CASPR2 contactin-associated protein 2, CBA cell-based assay, DR2 dopamine receptor 2, ELISA enzyme linked immunosorbent assay, $f C y t$ flow cytometry, GAD65 glutamic acid decarboxylase $65, n$ number, $N M D A R N$-methyl-D-aspartate receptor, $P C$ Purkinje cell, $V G K C$ voltage gated potassium channel

\section{Maternal-fetal transfer of fetal brain protein antibodies}

In our literature search, we identified one study Bauman et al. (2013) that assessed the effect on monkeys of the maternal-fetal transfer of fetal brain protein antibodies with a molecular weight of 37 or $73 \mathrm{kDa}$. They investigated the behavior of macaques given IgG from mothers whose children were autistic (IgG-ASD) in their second or third trimester of pregnancy for a long 2-year period. The eight macaques with IgG-ASD exhibited inappropriate social interaction, namely more frequent contacts with familiar and unfamiliar peers than the controls. These findings could imply a more aggressive, impulsive and social not effective behavior of these macaques with IgG-ASD. Moreover, increased white matter volumes are observed in macaques with IgG-ASD, similar to the increased brain volume in young males with ASD (Nordahl et al. 2011). These results concur with abnormal behavior and also indicate structural abnormalities suggesting the induction of autistic behavior in macaques. These monkeys are very suitable for animalmodel investigations, as their brain organization and social interaction reveal considerable similarities to us humans. In addition, another study confirms autistic behavior in mice with specific fetal brain autoantibodies (Jones et al. 2020) indicating antibody-mediated autoimmunity as a probable mechanism that might be species independent.

\section{Psychiatric syndromes and disorders in children associated with neuronal autoantibodies}

The possible effects of a transfer of maternal autoantibodies to newborns could have consequences for the functional, intellectual, and social abilities of children as mentioned in animal and human studies above. Below we report on psychiatric syndromes and disorders associated with neuronal autoantibodies (Table 2).

Table 2 Important clinical features as indicators for autoimmune involvement in children

Acute regression in childhood development

Altered level of consciousness

Altered mental status

Catatonia

Cognitive dysfunction

Dynamic psychopathology

Focal neurological deficits

Lack of treatment response (antidepressants, antipsychotics)

Movement disorder

Psychiatric symptoms

Seizures not explained by a known epilepsy

Complemented and modified from Cellucci et al. (2020) 


\section{Psychosis}

Psychosis in children is characterized by obvious disturbances in their behavior, mental activity, and perception (for review see McClellan 2018). In 54\% of 43 patients with first-episode psychosis, dopamine 2-receptor antibodies and NMDAR-receptor antibodies were detected in the children's serum (Pathmanandavel et al. 2015) (Table 1). The differential diagnosis of psychosis is very important, as psychosis can be also a symptom of a basal ganglia encephalitis with dopamine receptor 1 (DR1) and DR2 antibodies in Syndenham chorea and PANDAS (Chain et al. 2020; Pollak et al. 2020). An animal study proved that autoantibodies from patients with Sydenham chorea target the DR2 on neurons (Cox et al. 2013) suggesting a pathogenic link between the evolution of psychotic symptoms and dopamine receptor autoimmunity. In other case series, patients presenting a first-episode psychosis revealed serum thyroid antibodies in conjunction with auditory and visual hallucinations as the predominant clinical features. CSF NMDAR antibodies are known to be associated with aggression, and there is evidence that serum LGI1 antibodies are associated with aggression and sleep disturbance (AlHakeem and Tabrki 2017). The presence of CSF NMDAR antibodies in patients suffering a first-episode psychosis suggests strong evidence of autoimmunity. Pediatric NMDAR encephalitis represents a large amount of all NMDAR encephalitis cases, and is usually associated with seizures and abnormal movements, while adults present more often with psychiatric disorders. Nevertheless, pediatric psychosis accompanying anti-NMDAR encephalitis has also been reported (Brenton et al. 2016): subtypes of psychosis might thus have an autoimmune origin in children. However, the latest evidence supports an autoimmune origin of psychosis in children associated with neural cell-surface autoantibodies only when additional clinical features or paraclinical findings of autoimmune encephalitis (Cellucci et al. 2020) occur in conjunction. The psychopathology of psychosis will be described in more depth in future studies to help us more accurately determine which patients require a sophisticated diagnostic approach to detect autoantibodies.

\section{Attention-deficit hyperactivity disorder}

Attention-deficit hyperactivity disorder (ADHD) is a disorder in children whose clinical features are inattention, disorganization, or hyperactivity-impulsivity; it constitutes a frequent neurodevelopmental disorder that can persist into adulthood (for review see Cabral et al. 2020). GAD65 antibodies were detected in $27 \%$ of 15 children with ADHD, but in none of the controls. However, as the titer of antibodies did not correlate with mental retardation (Rout et al. 2012) and the GAD65 antibodies were detected in serum, the evidence for autoimmunity is low. Dopamine transporter (DAT) autoantibodies are a potential marker of the psychopharmacological treatment response, as basal DAT antibodies are elevated in untreated patients with ADHD (Giana et al. 2015). Considered together, there is little evidence from subgroups of ADHD patients with potentially autoimmunemediated symptoms. More thorough investigation is necessary to further clarify the pathogenic relevance of these serum antibodies.

\section{Autism spectrum disorders}

Autism spectrum disorders (ASD) in children are defined by repetitive behavior or activities culminating in social-interaction deficits (for review see, Mughal et al. 2020). There is low to moderate probability for autoimmunity in ASD, as made evident through studies showing proven serum autoantibodies to brain proteins [often not specified, i.e., antibodies against proteins 37, 39, 45, 62, $73 \mathrm{kDa}$ (Rossi et al. 2013; Piras et al. 2014)]. $45 \mathrm{kDa}$ protein antibodies are known to correlate with autism severity, as indicated by cognitive impairment and lower scores on behavioral scales in the Piras et al. study (2014), suggesting that specific brain autoantibodies play a pathophysiological role in inducing or exacerbating autistic symptoms. That assumption is further corroborated by their findings (Piras et al. 2014) that maternal 37, 39 and $73 \mathrm{kDa}$ autoantibodies correlate with the verbal and non-verbal capacities of ASD children, and that the $62 \mathrm{kDa}$ autoantibody is associated with more stereotypical behavior. Furthermore, we noted serum anti-brain antibodies against the human frontal cortex in a mentally retarded group of ASD patients compared to depressed controls (Todd et al. 1988) implicating a possible role of frontal cortex immunity in ASD. However, the evidence for such autoimmunity located within the frontal cortex is low, and further investigations entailing CSF analyses are needed. Interestingly, the evidence of elevated specific serum antibodies such as antibodies against lactate dehydrogenase (LDH), stress-induced phosphoprotein 1 (STIP1), collapsin response mediator protein 1 (CRMP1), or cypin from mothers with ASD children displaying stereotypical behaviors (Braunschweig et al. 2013) adds credence to the relationship between the maternal-fetal transfer of autoantibodies and induction of autistic behavior. The role these autoantibodies play in worsening neurodevelopment is further supported by the role they play in cell migration (Braunschweig et al. 2013), apoptosis (Charrier et al. 2006), gray matter integrity (Yum et al. 2017) and dendritic organization (Patel et al. 2018; Ariza et al. 2017). A major challenge is to characterize these aforementioned and other autoantibodies, thereby confirming their pathogenic relevance through CSF studies, and to delineate their role better within the induction of autistic behavior. 


\section{Obsessive-compulsive disorder}

Obsessive-compulsive disorder (OCD) is defined by obsessions in combination with compulsions that mildly to severely impair the patient's quality of life (for review see, Nazeer et al. 2020). Increased serum antibodies against basal ganglia (ABGA), Dopamin 1 receptor (DR1) and lysoganglioside have been detected in patients with OCD compared to controls (Dale et al. 2005; Cox et al. 2015). However the pathogenicity of ABGA antibodies is highly doubtful (Dale and Brilot 2012). Furthermore, OCD associated with membrane surface autoantibodies must be distinguished from PANS. It is worth carrying out further studies involving CSF analysis to disentangle the significance of these autoantibodies regarding symptoms and disease generation.

\section{Tics and Gilles de la Tourette syndrome}

Tics and Gilles de la Tourette syndrome (TS) are hyperkinetic movement disorders in childhood. Tics appear suddenly and are non-rhythmic, involving often repetitive motor movements or phonic tics (vocalizations), whereas TS is characterized by both motor and phonic tics persisting for more than a year (for review see Mittal 2020). Autoantibodies against two not-further-specified proteins $(55,86 \mathrm{kDa})$ were identified in 21 patients with TS (Morer et al. 2008). There are no investigations that analyzed CSF autoantibodies in children with TS.

\section{Catatonia}

Catatonia is characterized by immobility and stupor, posturing, mutism and waxy flexibility, echolalia, and an excitatory phase characterized by bizarre, non-goal-directed hyperactivity. This syndrome has been historically considered as pathognomonic for schizophrenia, but it is also present in other psychiatric (e.g., depression) and neurological disorders. Immunological processes are increasingly implicated as causes for catatonia in the field (Rogers et al. 2019). Pediatric catatonia is defined as "organic" in approximately $20 \%$ of patients, and is also associated with PANDAS and pediatric autoimmune encephalitis (Lahutte et al. 2008). Antibodymediated catatonia has not just been diagnosed-it has also been treated successfully in children with systemic lupus erythematosus, anti-NMDAR encephalitis (Consoli et al. 2012) and $\mathrm{GABA}_{\mathrm{A}}$ receptor encephalitis (Nikolaus et al. 2018). Importantly, catatonia in these cases (Consoli et al. 2012) was accompanied by polysymptomatic neurological abnormalities like seizures, movement disorders and by multisystemic features of systemic lupus erythematosus. Screening for autoantibodies against neuronal surface antigens and CSF analysis should thus be considered in children suffering from catatonia.

\section{Igniting an autoimmune attack in children}

We have reported on observing the fetal transfer of maternal neuronal autoantibodies and consequences for dysfunctional behavior and brain damage in animal models. Furthermore, we have reported psychiatric syndromes or disorders associated with serum neuronal autoantibodies in children. NMDAR, CASPR2 as well as $37 \mathrm{Da}$ and $73 \mathrm{k}$ Da fetal brain autoantibodies are believed to be pathogenic as these antibodies constitute cell-surface antibodies. Antibody studies have pointed out the pathogenicity of NMDAR (Malviya et al. 2017) and CASPR2 (Saint-Martin et al. 2019) in humans. A probable autoimmune disease was induced in animal models (Wang et al. 2012; Jurek et al. 2019; Lee et al. 2009a, b; Coutinho et al. 2017a, b; Brimberg et al. 2016; Bagnall-Moreau et al. 2020) as tissue investigations and behavioral analysis, suggesting a pathogenic role of these autoantibodies. However, as psychiatric symptoms are difficult to assess in animals, specific symptoms such as hyperlocomotion can be interpretated as surrogate behavior suggesting, for example, mania or ADHD like symptoms. Thus, keeping the difficulty of assessing psychiatric symptoms in animals in mind, we can reproduce a disease caused by the transfer of autoantibodies triggering brain damage and inducing abnormal behavior. Moreover, we have clinical hints that children, like those with NMDAR antibodies and psychosis (Pathmanandavel et al. 2015) and children with CASPR2 antibodies and mental retardation (Coutino et al. 2017a, b) and 37 and $73 \mathrm{kDa}$ antibodies against fetal brain antibodies in combination with ADHD symptoms (Rossi et al. 2013) might bear clues for an autoimmune disease associated with behavioral abnormalities. We thus believe that NMDAR, CASPR 2 and 37 and $73 \mathrm{kDa}$ against fetal brain protein antibodies are pathogenic. Taken together, Whitebsky's revised criteria for an autoimmune disease are fulfilled, and reflect the pathogenicity of these autoantibodies in children (Rosa and Bone 1993). However, there have been no studies assessing the long-term effects of autoimmune encephalitis or antibody-associated psychiatric syndrome over years or decades to evaluate whether such an initial hit could be the trigger for the initial manifestation of psychiatric disorders. Furthermore, a recent study by Hammer et al. (2014) found that the antibody presence in schizophrenia patients was associated with a history of birth complications or brain injury. It is therefore conceivable that brain injury could lead to NMDAR antibody seropositivity. However, the pathogenic role of NMDAR antibodies in the development of schizophrenia is not supported by their findings. Moreover, they detected no phenotypic differences in patients with schizophrenia with or without NMDAR antibodies in their study. NMDAR antibodies are believed to be pathogenic 
in NMDAR encephalitis (Malviya et al. 2017) and in NMDAR antibody-associated psychosis via a reorganization of synaptic NMDARs (Jézéquel et al. 2017). Further longitudinal studies in transition psychiatry in children with early neuroglial autoantibodies in their lifetime will have to be conducted to find out how relevant these neuroglial antibodies in early childhood may be in later adult life in generating psychiatric symptoms.

There are autoimmune encephalopathies characterized by their chronic relapse-remitting character, such as GAD65 autoimmune encephalitis (Hansen et al. 2018), which probably disturbs brain function and structure repeatedly and may lead to permanent deficits resulting in the manifestation of psychiatric disease. Furthermore, a recent report suggested that a patient who recovered from LGI1- encephalitis developed a new onset psychotic disorder after surviving a one-year course of LGI1-antibody-positive encephalitis (Pollak and Moran 2017). This is a paradigmatic example of how a subsiding or chronic, recurrent autoimmune encephalitis with circulating serum or cerebrospinal fluid autoantibodies may influence psychiatric disorders. However, the underlying mechanism of circulating serum autoantibodies that may permeate the blood-brain barrier temporarily due to a transient dysfunction of the blood-brain barrier in early childhood must be differentiated from that of the maternal-fetal transfer of brain autoantibodies. However, if the blood-brain barrier is impervious, the underlying mechanism remains obscure in children with circulating serum autoantibodies. We postulate that both mechanisms [(a) fetal transfer and (b) circulating autoantibodies] contribute to our "autoimmune-priming-attack hypothesis". An early autoimmune process during autoimmune encephalitis, autoimmune psychosis (Pollak et al. 2020), autoimmune dementia (Flanagan et al. 2010) or an antibody-associated psychiatric syndrome (Hansen et al. 2020) could occur at a critical stage in human neurodevelopment, thereby affecting either the structure or function of CNS development. Thus, although the autoimmune process appears to recover (verified by the lack of autoantibodies), residual structural and functional deficits may be sowing the breeding ground for the development of specific subgroups of psychiatric disease. Furthermore, impaired brain development due to circulating antibodies could be a risk factor for a later psychiatric disease onset in case of a "second hit" (e.g., drug consumption, life events, etc.). Our "autoimmunepriming-attack hypothesis" could be especially relevant for behavioral disorders such as ASD or ADHD, but also psychotic disorders. In the next section, we report on several autoantibodies-associated psychiatric disorders in childhood.

\section{Autoantibody-based psychiatric syndrome in children}

We recommend classifying the appearance of psychiatric symptoms lasting under 3 months as subacute psychiatric syndrome (aPS), and those lasting more than 3 months as a subchronic psychiatric syndrome (cPS) providing additional criteria are fulfilled (Fig. 2) in analogy to previously published criteria according to Hansen et al. for adults (2020). Furthermore, these criteria are based on recently published criteria for autoimmune encephalitis in children (Cellucci et al. 2020). A possible autoimmune a/cPS (a/cAPS) should be presumed if a subacute psychiatric syndrome is present in addition with the existence $\geq 2$ indicators of autoimmunity listed in Table 2. To assume a probable a/c APS $\geq 1$, features in paraclinical investigations must be fulfilled. These criteria indicate an autoimmune origin and comprise additional items based on an inflammation (pleocytosis with $\geq 5 / \mu \mathrm{l}$ or intrathecal IgG synthesis) in the cerebrospinal fluid (CSF), focal or generalized epileptic potentials or focal slowing in the electroencephalography (EEG) and/or features often found in the temporal lobe in magnetic resonance imaging (MRI) investigations indicating encephalitis (Fig. 2) or via an inflammation detected in a brain biopsy after excluding other diseases. Autoantibody positivity in serum or CSF leads to the occurrence of a definitive a/cAPS if $\geq 1$ paraclinical findings are present. However, if MOG, NMDAR or GAD65 antibodies are found in the CSF, no further paraclinical findings are important to diagnose a definitive a/cAPS. The presence of serum neural cell-surface autoantibody positivity is not necessary to assume a probable a/cAPS. The no-proof-of-neuroglial-autoantibodies condition in conjunction with other clinical and paraclinical features suggesting probable a/cAPS is termed seronegative a/cAPS. Further markers suggest brain damage, but are not marker-established (such as elevated neuroglial proteins) for diagnosing an APS. Furthermore, CSF neopterin in children seems to be a promising marker for neuroinflammation (Molero-Luis et al. 2020). We recommend searching for a specific autoantibody panel in serum and CSF according to suggested antibodies for autoimmune pediatric encephalitis (Cellucci et al. 2020) and considering results from our literature research. The autoantibody panel consists of autoantibodies against NMDAR, MOG, GAD65, GABAAR for initial screening, and if those are negative but there are further hints suggesting an autoimmune condition, the antibodies that should be determined are: ABGA, CASPR2, LGI1, DAT, DR2, DR1, mGluR5, Glycin and GABABR. The testing in serum and CSF is necessary, as the sensitivity for detecting antibodies differs between serum and CSF depending on the autoantibody being tested. In addition, we advise using cell-based assays for serum and CSF antibody testing when searching for antibodies against membrane surface antigens and 
enzyme-linked immunosorbent assays (ELISA) combined with absorption-spectrometry when seeking GAD65 antibodies. The antibody's relevance is assessed in the second step via tissue-based systems; immunofluorescence and immunohistochemistry should confirm the detected autoantibodies from the first step. Differential diagnoses and ruling out other diagnoses are important steps in diagnosing APS. Careful exclusion of differential diagnoses must be undertaken, considering brain trauma, systemic inflammatory and primary CNS inflammatory disorders such as infectious encephalitis, infectious meningoencephalitis or infection-associated encephalopathy, diseases with postulated immune mechanisms, malignancies, intoxications, nutritional, neoplastic, metabolic, psychiatric or endocrine disorders, electrolyte disturbances, epilepsy as well as nonconvulsive status epilepticus.

\section{Discussion}

\section{Synopsis: autoantibody-associated psychiatric syndromes in children}

We identified six major groups of psychiatric disorders known to be associated (and appearing in subgroups) with diverse serum neuronal autoantibodies. Further research entailing the investigation of specific antibodies, clinical features (Table 2) and inflammation markers in CSF is required to be able to claim a probable autoimmune etiology in subgroups of these patients.

\section{Diagnostic aspects}

We recommend promoting CSF testing in the aforementioned patient groups, as it is currently the only way to prove IgG autoantibodies in the CSF of definitive autoimmune origin (Fig. 2). As an initial approximation serum analysis could be helpful, if lumbar puncture is not accessible or tolerable. Nevertheless, we advise its use for severely affected patients presenting these assumed diagnoses: psychosis, catatonia, ASD, OCD, ADHD, TS or other tics. Furthermore, the symptoms below should lead clinicians to carry out more thorough diagnostics as exemplified in Fig. 2: psychosis, inattention, hyperactivity, impulsivity, obsessions, compulsions, motor and phonic tics as well as catatonia.

\section{Ethical considerations}

Although no evidence of CSF autoantibodies-associated ASD, OCD, ADHD, TS, catatonia or other tics has been identified to date, we recommend performing CSF analysis to detect IgG antibodies establishing a more probable autoimmunity. However, important issues must be carefully considered beforehand, namely a thorough consent procedure and consultation clarifying its main benefits and risks. The child's parent or parents or legal guardian would have to agree and provide written consent. Furthermore, immunotherapy in children with autoimmune encephalitis (for review, see Garg et al. 2020; Zuliani et al. 2019) and autoimmune-based psychiatric syndromes is an optional therapy whose evidence level is low to moderate (evidence level IV through case control and cohort studies). However, it is not within the scope of our article to make recommendations for specific treatment, as no meta-analyses or randomized placebo control studies have been conducted in autoantibodybased psychiatric syndromes in children. Before administering immunotherapeutic treatment, the child's custodian again would have to give their written permission and be informed that this is an experimental treatment given on an individual therapeutic trial basis.

\section{Limitations}

The clinical significance of the reported neural serum antibodies associated with psychiatric disorders is unknown and questionable apart from the NMDAR antibodies believed to be pathogenic. GAD65 antibodies are described in children presenting well-known clinical disorders such as stiff-person syndrome, temporal lobe epilepsy or cerebellar ataxia, but much less is known about their occurrence in pediatric psychiatric syndromes. Their pathogenic relevance is dependent on high serum and CSF titers (Cellucci et al. 2020). Further large-scale studies are required to validate the clinical significance of these antibody findings. Although the evidence level is low and no descriptions about which antibody tests were made, we cited a single case from Al Hakeem et al. (Al Hakeem and Tabarki 2016) mentioning IgG NMDAR antibodies in CSF in association with aggression. Further studies in large patient cohorts are necessary to validate and confirm these preliminary findings.

\section{Conclusions}

The maternal-fetal transfer of autoantibodies during gestation may be how a mother's autoimmune encephalitis can trigger an autoimmune hit in her child ("autoimmune-priming-attack hypothesis"). Autoantibody-associated psychiatric disorders in childhood are subentities of psychosis, ADHD, ASD, OCD, catatonia or TS. We have created a clinical pathway based on our literature review indicating when to use specific diagnostic methods for identifying patients presenting underlying autoimmunity.

Acknowledgements JW is supported by an Ilídio Pinho professorship, iBiMED (UIDB/04501/2020) at the University of Aveiro, Portugal. 
Author contributions NH, AN and DL wrote the manuscript. All other authors revised the manuscript for important intellectual content.

Funding Open Access funding enabled and organized by Projekt DEAL.

\section{Declarations}

Conflict of interest The authors have no conflict of interest to declare.

Open Access This article is licensed under a Creative Commons Attribution 4.0 International License, which permits use, sharing, adaptation, distribution and reproduction in any medium or format, as long as you give appropriate credit to the original author(s) and the source, provide a link to the Creative Commons licence, and indicate if changes were made. The images or other third party material in this article are included in the article's Creative Commons licence, unless indicated otherwise in a credit line to the material. If material is not included in the article's Creative Commons licence and your intended use is not permitted by statutory regulation or exceeds the permitted use, you will need to obtain permission directly from the copyright holder. To view a copy of this licence, visit http://creativecommons.org/licenses/by/4.0/.

\section{References}

Alarcón M, Abrahams BS, Stone JS, Duvall JA, Perederiy JA, Bomar $\mathrm{JM}$ et al (2008) Linkage, association, and gene-expression analyses identify CNTNAP2 as an autism-susceptibility gene. Am J Hum Genet 82:150-159. https://doi.org/10.1016/j.ajhg.2007.09. 005

AlHakeem AS, Tabarki B (2017) Acute psychosis in children: do not miss immune-mediated causes. Neurosciences (riyadh) 21:252255. https://doi.org/10.17712/nsj.2017.1.20160552

Ariza J, Hurtado J, Rogers H, Ikeda R, Dill M, Steward C, Creary D et al (2017) Maternal autoimmune antibodies alter the dendritic arbor and spine numbers in the infragranular layers of the cortex. PLoS ONE 12:e0183443. https://doi.org/10.1371/journal.pone. 0183443

Armangue T, Moris G, Cantarín-Extremera V, Conde CE, Rostasy K, Erro ME et al (2015) Spanish Prospective Multicentric Study of Autoimmunity in Herpes Simplex Encephalitis. Autoimmune post-herpes simplex encephalitis of adults and teenagers. Neurology 85:1736-1743. https://doi.org/10.1212/WNL.0000000000 002125

Bagnall-Moreau C, Huerta PT, Comoletti D, La-Bella A, Berlin RZ et al (2020) In utero exposure to endogenous maternal polyclonal anti-Caspr2 antibody leads to behavioral abnormalities resembling autism spectrum disorder in male mice. Sci Rep 2(10):14446. https://doi.org/10.1038/s41598-020-71201-9

Bauman MD, Iosif AM, Ashwood P, Braunschweig D, Lee A, Schumann CM et al (2013) Maternal antibodies from mothers of children with autism alter brain growth and social behavior development in the rhesus monkey. Transl Psychiatry 3:e278. https://doi. org/10.1038/tp.2013.47

Bien CG, Bien CG, Mirzadjanova Z, Baumgartner C, Onugoren MD, Grunwald T, Holtkamp M (2017) Anti-contactin-associated protein-2 encephalitis: relevance of antibody titres, presentation and outcome. Eur J Neurol 24:175-186. https://doi.org/10.1111/ene. 13180

Braunschweig F, Krakowiak P, Duncanson P, Boyce R, Hansen RL et al (2013) Autism-specific maternal autoantibodies recognize critical proteins in developing brain. Transl Psychiatry 3:e277. https://doi. org/10.1038/tp.2013.50

Brenton JN, Kim J, Schwartz RH (2016) Approach to the management of pediatric-onset anti-N-Methyl-d-aspartate (Anti-NMDA) receptor encephalitis: a case series. J Child Neurol 31:1150-1155. https://doi.org/10.1177/0883073816643406

Brimberg L, Mader S, Jeganathan V, Berlin R, Coleman TR, Gregersen PK et al (2016) Caspr2-reactive antibody cloned from a mother of an ASD child mediates an ASD-like phenotype in mice. Mol Psychiatry 21:1663-1671. https://doi.org/10.1038/mp.2016.165

Cabral MDI, Liu S, Soares N (2020) Attention-deficit/hyperactivity disorder: diagnostic criteria, epidemiology, risk factors and evaluation in youth. Transl Pediatr 9:S104-S113. https://doi.org/10. 21037/tp.2019.09.08

Cellucci T, Van Mater H, Graus F, Muscal E, Gallentine W, KleinGitelman MS et al (2020) Clinical approach to the diagnosis of autoimmune encephalitis in the pediatric patient. Neurol Neuroimmunol Neuroinflamm. https://doi.org/10.1212/NXI.00000 00000000663

Chain JL, Alvarez K, Mascaro-Blanco A, Reim S, Bentley R, Hommer R et al (2020) Autoantibody biomarkers for basal ganglia encephalitis in sydenham chorea and pediatric autoimmune neuropsychiatric disorder associated with streptococcal infections (PANDAS). Front Psych 11:564. https://doi.org/10.3389/ fpsyt.2020.00564

Charrier E, Mosinger B, Meissirel C, Aguera M, Rogemond V, Reibel $\mathrm{S}$ et al (2006) Transient alterations in granule cell proliferation, apoptosis and migration in postnatal developing cerebellum of CRMP1-/- mice. Genes Cells 11:1337-1352. https://doi org/10.1111/j.1365-2443.2006.01024.x

Coley A, Gao WJ (2018) PSD95: a synaptic protein implicated in schizophrenia or autism? Prog Neuropsychopharmacol Biol Psych 82:187-194. https://doi.org/10.1016/j.pnpbp.2017.11.016

Consoli A, Raffin M, Laurent C, Bodeau N, Campion D, Amoura Z et al (2012) Medical and developmental risk factors of catatonia in children and adolescents: a prospective case-control study. Schizophr Res 137:151-158. https://doi.org/10.1016/j.schres. 2012.02.012

Coutinho E, Jacobson L, Pedersen MG, Benros ME, NørgaardPedersen B, Mortensen PB, Harrison PJ, Vincent A (2017a) CASPR2 autoantibodies are raised during pregnancy in mothers of children with mental retardation and disorders of psychological development but not autism. J Neurol Neurosurg Psychiatry 88:718-721. https://doi.org/10.1136/jnnp-2016-315251

Coutinho E, Menassa DA, Jacobson L, West SJ, Domingos J, Moloney TC et al (2017b) Persistent microglial activation and synaptic loss with behavioral abnormalities in mouse offspring exposed to CASPR2-antibodies in utero. Acta Neuropathol 134:567-583. https://doi.org/10.1007/s00401-017-1751-5

Cox CJ, Sharma M, Leckman JF, Zuccolo J, Zuccolo A, Kovoor A et al (2013) Brain human monoclonal autoantibody from Sydenham chorea targets dopaminergic neurons in transgenic mice and signals dopamine D2 receptor: Implications in human disease. J Immunology 191:5524-5541. https://doi.org/10.4049/ jimmunol.1102592

Cox CJ, Zuccolo AJ, Edwards EV, Mascaro-Blanco A, Alvarez K, Stoner J et al (2015) Antineuronal antibodies in a heterogeneous group of youth and young adults with tics and obsessive-compulsive disorder. J Child Adolesc Psychopharmacol 25:76-85. https://doi.org/10.1089/cap.2014.0048

Dale RC, Brilot F (2012) Autoimmune basal ganglia disorders. J Child Neurol 27(11):1470-1481. https://doi.org/10.1177/0883073812 451327

Dale RC, Heyman I, Giovannoni G, Church AWJ (2005) Incidence of anti-brain antibodies in children with obsessive-compulsive 
disorder. Br J Psychiatry 187:314-319. https://doi.org/10.1192/ bjp.187.4.314

Dalmau J (2020) Pregnancy, N-Methyl-D-aspartate receptor antibodies, and neuropsychiatric diseases. Ann Neurol 87:324-325. https://doi.org/10.1002/ana.25654

Feki S, Turki A, Frikha F, Hachicha H, Walha L, Gargouri BZ et al (2015) Neonatal lupus and maternofetal transmission of antiSSA/Ro and anti-SSB/La antibodies. Arch Pediatr 22:154-159. https://doi.org/10.1016/j.arcped.2014.10.020

Flanagan EP, McKeon A, Lennon VA, Boeve BF, Trenerry MR, Tan MK (2010) Autoimmune dementia: clinical course and predictors of immunotherapy response. Mayo Clin Proc 85-:881-897. https://doi.org/10.4065/mcp.2010.0326

Florance NR, Davis RL, Lam C, Szperka C, Zhou L, Ahmad S (2009) Anti-N-methyl-D-aspartate receptor (NMDAR) encephalitis in children and adolescents. Ann Neurol 66:11-18. https://doi.org/ 10.1002/ana.21756

Garg D, Mohammad SS, Sharma S (2020) Autoimmune encephalitis in children: an update. Indian Pediatr 57:662-670 (PMID: 32727942)

Giana G, Romano E, Porfirio MC, D’Ambrosio R, Giovinazzo S, Troianiello M, et al (2015) Detection of auto-antibodies to DAT in the serum: interactions with DAT genotype and psycho-stimulant therapy for ADHD. J Neuroimmunol 278:212-222. https:// doi.org/10.1016/j.jneuroim.2014.11.008

Gilbert DL (2019) Inflammation in tic disorders and obsessive-compulsive disorder: are PANS and PANDAS a path forward? J Child Neurol 34:598-611. https://doi.org/10.1177/0883073819848635

Gromark C, Harris RA, Wickström R, Horne AC, Silverberg-Mörse M, Eva Serlachius E, Mataix-Cols D (2019) Establishing a pediatric acute-onset neuropsychiatric syndrome clinic: baseline clinical features of the pediatric acute-onset neuropsychiatric syndrome cohort at Karolinska Institutet. J Child Adolesc Psychopharmacol 29:625-633. https://doi.org/10.1089/cap.2018. 0127

Hacohen Y, Wright S, Waters P, Agrawal S, Carr L, Cross H et al (2013) Paediatric autoimmune encephalopathies: clinical features, laboratory investigations and outcomes in patients with or without antibodies to known central nervous system autoantigens. J Neurol Neurosurg Psychiatry 84:748-755. https://doi.org/10.1136/ jnnp-2012-303807

Hammer C, Stepniak B, Schneider A, Papiol S, Tantra M, Begemann M, Sirén AL, Pardo LA, Sperling S, Mohd Jofrry S, Gurvich A, Jensen N, Ostmeier K, Lühder F, Probst C, Martens H, Gillis M, Saher G, Assogna F, Spalletta G, Stöcker W, Schulz TF, Nave KA, Ehrenreich H (2014) Neuropsychiatric disease relevance of circulating anti-NMDA receptor autoantibodies depends on bloodbrain barrier integrity. Mol Psychiatry 19:1143-1149. https://doi. org/10.1038/mp.2013.110

Hansen N, Ernst L, Rüber T, Widman G, Becker AJ, Elger CE et al (2018) Pre- and long-term postoperative courses of hippocampus-associated memory impairment in epilepsy patients with antibody-associated limbic encephalitis and selective amygdalohippocampectomy. Epilepsy Behav 79:93-99. https://doi.org/10. 1016/j.yebeh.2017.10.033

Hansen N, Lipp M, Vogelgsang J, Vukovich R, Zindler T, Luedecke D, + CAP (Cerebrospinal Fluid Analysis in Psychiatry) Consortium et al (2020) Autoantibody-associated psychiatric symptoms and syndromes in adults: a narrative review and proposed diagnostic approach. Brain Behav Immunity Health 9:100154. https://doi. org/10.1016/j.bbih.2020.100154

Herken J, Prüss H (2017) Red flags: clinical signs for identifying autoimmune encephalitis in psychiatric patients. Front in Psychiatry 8:25. https://doi.org/10.3389/fpsyt.2017.00025

Hon KL, Leung AKC, Torres AR (2018) Febrile infection-related epilepsy syndrome (FIRES): an overview of treatment and recent patents recent pat. Inflamm Allergy Drug Discov 12:128-135. https://doi.org/10.2174/1872213X12666180508122450

Jézéquel J, Johansson EM, Dupuis JP, Rogemond V, Gréa H, Kellermayer B, Hamdani N, Le Guen E, Rabu C, Lepleux M, Spatola M, Mathias E, Bouchet D, Ramsey AJ, Yolken RH, Tamouza R, Dalmau J, Honnorat J, Leboyer M, Groc L (2017) Dynamic disorganization of synaptic NMDA receptors triggered by autoantibodies from psychotic patients. Nat Commun 8(1):1791. https:// doi.org/10.1038/s41467-017-01700-3

Jones KL, Pride MC, Edmiston E, Yang M, Silverman JL, Crawley JN et al (2020) Autism-specific maternal autoantibodies produce behavioral abnormalities in an endogenous antigen-driven mouse model of autism. Mol Psychiatry 25:2994-3009. https://doi.org/ 10.1038/s41380-018-0126-1

Jurek B, Chyka M, Kreye J, Lang K, Kraus L, Fidzinski P et al (2019) Human gestational N-methyl-d-aspartate receptor autoantibodies impair neonatal murine brain function. Ann Neurol 86:656-670. https://doi.org/10.1002/ana.25552

Kim JS, Kornhuber HH, Schmid-Burgk W, Holzmüller B (1980) Low cerebrospinal fluid glutamate in schizophrenic patients and a new hypothesis on schizophrenia. Neurosci Lett 20:379-382. https:// doi.org/10.1016/0304-3940(80)90178-0

Kirvan CA, Swedo SE, Heuser JS, Cunningham MW (2003) Mimicry and autoantibody-mediated neuronal cell signaling in Sydenham's chorea. Nat Med 9:914-920. https://doi.org/10.1038/nm892

Kirvan CA, Swedo SE, Snider LA, Cunningham MW (2006) Antibodymediated neuronal cell signaling in behavior and movement disorders. J Neuroimmunol 179:173-179. https://doi.org/10.1016/j. jneuroim.2006.06.017

Lahutte B, Cornic F, Bonnot O, Consoli A, An-Gourfinkel I, Amoura Z, Sedel F, Cohen D (2008) Multidisciplinary approach of organic catatonia in children and adolescents may improve treatment decision making. Prog Neuropsychopharmacol Biol Psychiatry 32:1393-1398. https://doi.org/10.1016/j.pnpbp.2008.02.015

Lee JY, Huerta PT, Zhang J, Kowal C, Bertini E, Volpe BT, Diamond B (2009a) Maternal lupus and congenital cortical impairment. Nat Med 15:91-96. https://doi.org/10.1038/nm.1892

Lee JY, Huerta PT, Zhang J, Kowal C, Bertini E, Volpe BT, Diamond B (2009b) Neurotoxic autoantibodies mediate congenital cortical impairment of offspring in maternal lupus. Nat Med 15:91-96. https://doi.org/10.1038/nm.1892

Ma J, Zhang L-Q, He Z-X, He X-X, Wang Y-J, Jian Y-L, Wang X et al (2019) Autism candidate gene DIP2A regulates spine morphogenesis via acetylation of cortactin. PLoS Biol 17:e3000461. https:// doi.org/10.1371/journal.pbio.3000461

Malviya M, Barman S, Golombeck KS, Planagumà J, Mannara F, Strutz-Seebohm N et al (2017) NMDAR encephalitis: passive transfer from man to mouse by a recombinant antibody. Ann Clin Transl Neu 4:768-783. https://doi.org/10.1002/acn3.444

Mattozzi S, Sabater L, Escudero AH, Armangue T, Simabukuro M et al (2020) Hashimoto encephalopathy in the 21 st century. Neurology 14(94):e217-e224. https://doi.org/10.1212/WNL.00000 00000011101

McClellan J (2018) Psychosis in Children and Adolescents. J Am Acad Child Adolesc Psychiatry 57:308-312. https://doi.org/10.1016/j. jaac.2018.01.021

Mittal SO (2020) Tics and Tourette's syndrome. Drugs Context. https:// doi.org/10.7573/dic.2019-12-2

Molero-Luis M, Casas-Alba D, Orellana G, Ormazabal A, Sierra C, Olivia C et al (2020) Cerebrospinal fluid neopterin as a biomarker of neuroinflammatory diseases. Sci Rep 10:18291. https://doi.org/ 10.1038/s41598-020-75500-z

Morer A, Lázaro L, Sabater L, Massana J, Castro J, Graus F (2008) (2008) Antineuronal antibodies in a group of children with obsessive-compulsive disorder and Tourette syndrome. J Psychiatr Res 42:64-68. https://doi.org/10.1016/j.jpsychires.2006.09.010 
Mughal S, Faizy RM, Saadabadi A (2020) Autism Spectrum Disorder (Regressive Autism, Child Disintegrative Disorder). StatPearls [Internet]. Treasure Island (FL): StatPearls Publishing

Murphy TK, Gerardi DM, Leckman JF (2014) Pediatric acute-onset neuropsychiatric syndrome. Psychiatr Clin North Am 37:353-374. https://doi.org/10.1016/j.psc.2014.06.001

Nazeer A, Latif F, Mondal A, Azeem MW, Greydanus DE (2020) Obsessive-compulsive disorder in children and adolescents: epidemiology, diagnosis and management. Transl Pediatr 9:76-93. https://doi.org/10.21037/tp.2019.10.02

Neniskyte U, Gross CT (2017) Errant gardeners: glial-cell-dependent synaptic pruning and neurodevelopmental disorders. Nat Rev Neurosci 18:658-670. https://doi.org/10.1038/nrn.2017.110

Nicollini H, López Y, Genis-Mendoza AD, Manrique V, Lopez-Canovas L, Niubo E (2015) Detection of anti-streptococcal, antienolase, and anti-neural antibodies in subjects with early-onset psychiatric disorders. Actas Esp Psiquiatr 43:35-41 (PMID: 25812540)

Nikolaus M, Knierim NM, Meisel C, Kreye J, Prüss H, Schnabel D, Kallinich T (2018) Severe GABA A receptor encephalitis without seizures: a paediatric case successfully treated with early immunomodulation. Eur J Paediatr Neurol 22:558-562. https://doi.org/ 10.1016/j.ejpn.2018.01.002

Nordahl CW, Lange N, Li DD, Barnett LA, Lee A, Buonocore MH, Simon TJ, Rogers $S$ et al (2011) Brain enlargement is associated with regression in preschool-age boys with autism spectrum disorders. Proc Natl Acad Sci USA 108:20195-20200. https://doi. org/10.1073/pnas.1107560108

Palmeira P, Quinello C, Silveira-Lessa AL, Zago CA, Carneiro-Sampaio $M$ (2012) IgG placental transfer in healthy and pathological pregnancies. Clin Dev Immunol 2012:985646. https://doi.org/10. $1155 / 2012 / 985646$

Patel MV, Swiatowski P, Kwon M, Rodriguez AR, Campagno K, Firestein BL (2018) A novel short isoform of cytosolic PSD-95 interactor (Cypin) regulates neuronal development. Mol Neurobiol 55:6269-6281. https://doi.org/10.1007/s12035-017-0849-z

Pathmanandavel K, Starling J, Merheb J, Ramanathan S, Sinmaz N, Dale RC, Brilot F (2015) Antibodies to surface dopamine-2 receptor and $\mathrm{N}$-methyl-D-aspartate receptor in the first episode of acute psychosis in children. Biol Psychiatry 77:537-547. https://doi.org/ 10.1016/j.biopsych.2014.07.014

Piras IS, Haapanen L, Napolioni V, Sacco R, Van de Water J, Persico AM (2014) Anti-brain antibodies are associated with more severe cognitive and behavioral profiles in Italian children with Autism Spectrum Disorder. Brain Behav Immun 38:91-99. https://doi. org/10.1016/j.bbi.2013.12.020

Pollak TA (2017) Moran N (2017) Emergence of new-onset psychotic disorder following recovery from LGI1 antibody-associated limbic encephalitis. BJM Case Rep. https://doi.org/10.1136/ bcr-2016-218328

Pollak T, Lennox BR, Müller S, Benros ME, Prüss H, Tebartz van Elst L et al (2020) Autoimmune psychosis: an international consensus on an approach to the diagnosis and management of psychosis of suspected autoimmune origin. Lancet Psychiatry 7:93-108. https://doi.org/10.1016/S2215-0366(19)30290-1

Quilter MC, Hiraki LT, Korczak DJ (2019) Depressive and anxiety symptom prevalence in childhood-onset systemic lupus erythematosus: a systematic review. Lupus 28:878-887. https://doi.org/ 10.1177/0961203319853621

Rogers JP, Pollak TA, Blackman G, David AS (2019) Catatonia and the immune system: a review. Lancet Psychiatry 6:620-630. https:// doi.org/10.1016/S2215-0366(19)30190-7

Rose NR, Bona C (1993) Defining criteria for autoimmune diseases (Witebsky's postulates revisited). Immunol Today 14:426-430. https://doi.org/10.1016/0167-5699(93)90244-F
Rossi CC, Fuentes J, Van de Water J, Amaral DG (2013) Brief report: antibodies reacting to brain tissue in Basque Spanish Children with Autism Spectrum Disorder and Their Mothers. J Autism Dev Disord. https://doi.org/10.1007/s10803-013-1859-y

Rout UK, Mungan NK, Dhossche DM (2012) Presence of GAD65 autoantibodies in the serum of children with autism or ADHD. Eur Child Adolesc Psychiatry 21:141-147. https://doi.org/10. 1007/s00787-012-0245-1

Saint-Martin M, Pieters A, Déchelotte B, Malleval C, Pinatel D, Pascual O et al (2019) Impact of anti-CASPR2 autoantibodies from patients with autoimmune encephalitis on CASPR2/TAG-1 interaction and Kv1 expression. J Autoimmun 103:102284. https://doi. org/10.1016/j.jaut.2019.05.012

Shimasaki C, Frye RE, Trifiletti R, Cooperstock M, Kaplan G, Melamed I et al (2020) Evaluation of the Cunningham PanelTM in pediatric autoimmune neuropsychiatric disorder associated with streptococcal infection (PANDAS) and pediatric acute-onset neuropsychiatric syndrome (PANS): Changes in antineuronal antibody titers parallel changes in patient symptoms. J Neuroimmunol 339:577138. https://doi.org/10.1016/j.jneuroim.2019. 577138

Sousa C, Golebiewska A, Poovathingal SK, Kaoma T, Pires-Afonso Y, Martina S et al (2018) Single-cell transcriptomics reveals distinct inflammation-induced microglia signatures. EMBO Rep 19:e46171. https://doi.org/10.15252/embr.201846171

Souza LC, Wilhelm EA, Bortolatto CF, Nogueira CW, Boeira SP, Jesse CR (2014) The protective effect of melatonin against brain oxidative stress and hyperlocomotion in a rat model of mania induced by ouabain. Behav Brain Res 271:316-324. https://doi.org/10. 1016/j.bbr.2014.06.030

Titulaer MJ, McCracken L, Gabilondo I, Armangué T, Glaser C, Iizuka $\mathrm{T}$ et al (2013) Treatment and prognostic factors for long-term outcome in patients with anti-NMDA receptor encephalitis: an observational cohort study. Lancet Neurol 12:157-165. https:// doi.org/10.1016/S1474-4422(12)70310-1

Todd RD, Hickok JM, Anderson GM, Cohen DJ (1988) Antibrain antibodies in infantile autism. Biol Psychiatry 23:644-647. https://doi. org/10.1016/0006-3223(88)90012-1

Varadkar S, Bien CG, Kruse CA, Jensen FE, Bauer J, Pardo CA, Vincent A, Mathern GW, Helen Cross J (2014) Rasmussen's encephalitis: clinical features, pathobiology, and treatment advances. Lancet Neurol 13:195-205. https://doi.org/10.1016/S1474-4422(13) 70260-6

Varea O, Martin-de-Saavedra KKJ, Schürmann B, Fleming HJ, Fawcett-Patel JM et al (2015) Synaptic abnormalities and cytoplasmic glutamate receptor aggregates in contactin associated protein-like 2/caspr2 knockout neuron. Proc Natl Acad Sci USA 112:61766181. https://doi.org/10.1073/pnas.1423205112

Wang L, Zhou D, Lee J, Niu H, Faust TM, Frattini S, Kowal C et al (2012) Female Mouse Fetal Loss Mediated by Maternal Autoantibody. J Exp Med 209:1083-1089. https://doi.org/10.1084/jem. 20111986

Yum SK, Moon C-J, Youn Y-A, Sung IK (2017) Changes in lactate dehydrogenase are associated with central gray matter lesions in newborns with hypoxic-ischemic encephalopathy. J Matern Fetal Neonatal Med 30:1177-1181. https://doi.org/10.1080/14767058. 2016.1208745

Zimmermann AM, Jene T, Wolf M, Görlich A, Gurniak CB, SassoèPognetto $\mathrm{M}$ et al (2015) Attention-deficit/hyperactivity disorderlike phenotype in a mouse model with impaired actin dynamics. Biol Psychiatry 78:95-106. https://doi.org/10.1016/j.biopsych. 2014.03.011

Zuliani L, Nosadini M, Gastaldi M, Spatola M, Spatola M, Iorio R, Zoccarato M et al (2019) Management of antibody-mediated autoimmune encephalitis in adults and children: literature review and 
consensus-based practical recommendations. Neurol Sci 40:20172030. https://doi.org/10.1007/s10072-019-03930-3

Zurgil N, Bakimer R, Tincani A, Faden D, Cohen J, Lorber M et al (1993) Detection of anti-phospholipid and anti-DNA antibodies and their idiotypes in newborns of mothers with anti-phospholipid syndrome and SLE. Lupus 2:233-237. https://doi.org/10.1177/ 096120339300200405
Publisher's Note Springer Nature remains neutral with regard to jurisdictional claims in published maps and institutional affiliations. 